\title{
Evidence for Clinical Safety, Efficacy, and Parent and Physician Perceptions of Levocetirizine for the Treatment of Children with Allergic Disease
}

\author{
A.N. Pampura ${ }^{a}$ N.G. Papadopoulos ${ }^{b}$ V. Špičák ${ }^{c} \quad$ R. Kurzawa ${ }^{d}$ \\ a Moscow Research Institute of Pediatrics and Children Surgery, Moscow, Russia; ${ }^{b}$ Allergy Department, \\ 2nd Pediatric Clinic, University of Athens, Athens, Greece; 'Paediatric Department, Faculty Hospital Bulovka, \\ Prague, Czech Republic; ${ }^{d}$ Department of Allergology and Pneumonology, National Research Institute for \\ Lung Diseases and Tuberculosis, Rabka-Zdrój, Poland
}

\section{Key Words}

Antihistamines $\cdot$ Allergic rhinitis $\cdot$ Levocetirizine $\cdot$

Paediatric population - Quality of life - Real-life study •

Pharmacodynamics - Pharmacokinetics - Total symptoms score $\cdot$ Urticaria

\begin{abstract}
Allergic rhinitis (AR) and chronic idiopathic urticaria (CIU) are highly burdensome diseases, which are increasing in prevalence, especially in the paediatric population. Despite the availability of a large number of medications for treatment of $A R$ and $C I U$, their use in children has primarily been based on data obtained from a limited number of clinical trials in children and/or testing in adults. The $\mathrm{H}_{1}$-antihistamines have traditionally been used as first-line treatment for the relief of both AR and CIU symptoms in children. The first-generation $\mathrm{H}_{1}$-antihistamines are associated with marked adverse effects such as sedation, sleepiness/drowsiness as well as difficulties in learning and cognitive processing; thus, they are recommended for limited or discontinued use in children with AR or CIU. In contrast, second-generation $\mathrm{H}_{1}$-antihistamines are more adapted for the use in children with AR and CIU due to better safety profiles. However, only a limited number of trials with these agents have been conducted and
\end{abstract}

generally, data from well-designed trials in children are lacking. Levocetirizine is one of the most extensively investigated $\mathrm{H}_{1}$-antihistamines for its pharmacologic properties, safety, efficacy as well as overall global satisfaction in children aged 2-12 years. Levocetirizine is the only $\mathrm{H}_{1}$-antihistamine launched in the 21st century shown to lack clinically relevant adverse effects on physical and psychomotor development or routine laboratory tests over a long-term period of 18 months in 1- to 3-year-old children predisposed to development of allergic disease. Available data suggest that levocetirizine is a suitable treatment option for AR and CIU in children aged 6 months to 12 years.

Copyright $\odot 2011$ S. Karger AG, Basel

\section{Introduction}

Evidence suggests that children do not generally respond to medications in the same way as adults, primarily due to differences in the metabolism, renal clearance and other drug disposition mechanisms associated with anatomical, physiological and developmental differences $[1,2]$. Moreover, there are age-related differences among children in their ability to metabolise, absorb, excrete and transform medications $[3,4]$. As paediatric formula-

\section{KARGER}

Fax +41613061234 E-Mail karger@karger.ch www.karger.com
(C) 2011 S. Karger AG, Basel

$1018-2438 / 11 / 1554-0367 \$ 38.00 / 0$

Accessible online at:

www.karger.com/iaa
Correspondence to: Dr. Alexander N. Pampura

Department of Allergology

Research Institute of Pediatrics and Children Surgery

Taldomscaja st. 2, RU-125412 Moscow (Russia)

Tel. +7 9262276 810, Fax +7 954833 335, E-Mail apampura1@ mail.ru 
tions, especially for children under 6 years of age, are usually in a liquid form, special knowledge and skills are necessary to make them stable, sterile, pleasant tasting, long lasting and with favourable pharmacokinetic (PK) as well as pharmacodynamic (PD) properties. Besides efficacy, compliance is also an important issue and adherence to treatment in the school-age children may be enhanced by pleasant taste, smell and ease of use of medication $[5,6]$. Similarly, specifically designed instruments, such as dropper pipettes are important for both convenient delivery and accurate dosing of liquid formulations, particularly because tableware teaspoons can vary in capacity and dosing errors may occur unless a measuring instrument is provided with the medication [7]. It is thus not surprising that development of paediatric formulations and the research associated with their development is often difficult and subject to several barriers, including ethical, economic, logistical, technical and regulatory ones [7-10]. Despite the general principles of the international guideline ICH E-11 [4], which dictate that paediatric patients should be given medicines that have been properly evaluated in the paediatric population with particular consideration of the PK/PD properties, efficacy and safety of the medicine in the relevant age categories [4], it is thought that $50-75 \%$ of the drugs prescribed for children have not been tested in paediatric populations [7].

Anti-allergic drugs, particularly the antihistamines and intranasal steroids, are among the most commonly prescribed medications in children as allergic rhinitis (AR) is currently one of the most common chronic disorder in the paediatric population. An increasing body of evidence indicates that allergies are becoming more persistent and complex, with most of today's AR patients being sensitised to multiple triggers and experiencing more severe and persistent symptoms [11]. It has been suggested that the increase in severity and persistence of symptoms of AR may be associated with multiple sensitisation and sustained exposure to traditional indoor allergens such as fungal and mould spores [12,13], as well as with prolonged exposure, due to extended pollen seasons, to perennial tree pollen, food and pet allergens [11]. Similarly, there is evidence that fossil fuel- (kerosene and gas) generated air pollutants in the home [11], indoor cleaning products [14], diet $[15,16]$ and psychological stress $[11,17]$ may increase the risk and/or sensitisation to allergens and contribute to the increasing prevalence of symptoms of AR.

Epidemiological studies suggest that the prevalence of $A R$ has increased progressively over the past 30 years in westernised societies and presently affects up to $40 \%$ of the population worldwide [18,19], with data from Europe indicating between 23 and $30 \%$ of the population being affected $[20,21]$ and data from the US indicating between 10 and $30 \%$ of adults being affected [22]. Importantly, data from studies in 6- to 14-year-old children have indicated that the prevalence of AR has doubled over the past two decades [23-26], with up to $40 \%$ of children being affected $[22,27]$. More recent data suggest that the prevalence of AR in children is still on the increase worldwide, although there are large variations among the countries, with more low- to mid-income countries showing increased prevalence [28].

The health and socioeconomic impact of AR on adults and society alike is well documented [29-32]. Reviews of studies in children have similarly indicated that the burden of AR in children is great. The symptoms of AR, apart from being bothersome, have the potential to lead to both physical and mental complications in children $[31,33]$. The physical complications are often associated with co-morbid conditions, including otitis media and effusion, recurrent and/or chronic sinusitis, snoring and asthma, whereas the mental complications are associated with sleep, poor school performance and hyperactivity, which can result in increased disturbances in learning, performance, behaviour and mood [31,33]. Indeed, the Pediatric Allergies in America survey [34] has recently provided compelling evidence that children with nasal allergies experience substantially more physical, mental, emotional and social problems than children who do not have allergies, and that the increased burden of symptoms frequently undermines restful sleep, leading to impairments in learning and cognition through absenteeism as well as activity avoidance [34]. The survey also indicated that healthcare providers overestimated the patients' and parents' satisfaction with disease management as well as the benefit of medications used for the treatment of nasal allergies in children, thus suggesting that the burden of AR on children was likely to be significantly underestimated [34].

\section{Management of AR in Paediatric Patients}

Treatment of AR in children involves the use of a variety of medications together with allergen and irritant avoidance measures, and can often be achieved in primary care for most patients [35]. Pharmacologic management encompasses the use of both over-the-counter (OTC) and prescription drugs including oral and intra- 
nasal $\mathrm{H}_{1}$-antihistamines, intranasal steroids (INS), decongestants, cromones, anti-leukotrienes and immunotherapy, of which the antihistamines and INS are most frequently used as first-line treatment, depending on the severity of symptoms of AR [34,35]. Decongestants are advised to be used for short periods of time, while antileukotrienes are increasingly used in patients with both AR and asthma.

Although immunotherapy has recently gained popularity in some parts of the world, this form of therapy may not always be available or possible, especially as it needs to be performed over a long period and under supervision by fully trained physicians [35]. Moreover, a systematic review of randomised controlled trials evaluating the effects of inhalant allergen immunotherapy (by cutaneous-, sublingual-, nasal- or oral-specific administration) on symptoms and medication use in 1,619 children and adolescents with allergic rhinoconjunctivitis showed that evidence for efficacy was conflicting and varied from being moderate to not effective [36]. As immunotherapy often involves treatment with a single allergen extract over a period of 3 years or more, it is possible that variation in efficacy documented by this systematic review was at least partly a consequence of sensitisation to multiple allergens and differences in experimental setting and design, patient selection and other parameters related to immunotherapy. Nevertheless, a position paper from the World Allergy Organisation has recently indicated that while subcutaneous immunotherapy is not generally prescribed to young children, primarily because of safety concerns, sublingual immunotherapy may lead to adverse events in $5-15 \%$ of the children younger than 5 years of age [37]. Furthermore, there are still many unmet needs with sublingual immunotherapy use in children, among which are the lack of optimal dose and dosing frequency of allergen administration, lack of data for longterm efficacy, duration of treatment, preventive capacity, sublingual immunotherapy use in preschool children, efficacy in patients unresponsive to pharmacotherapy and safety of sublingual immunotherapy with multiple allergens [37].

\section{Intranasal Steroids}

Although the INS are generally regarded as the treatment of choice and the gold standard for symptoms that are more than mild $[34,35]$, there is concern with unwanted systemic effects, including bone mineral loss, growth retardation, adrenal suppression and ocular disturbances, with long-term use in children. Moreover, the Pediatric Allergies in America survey [34] has indicated that about one third of the children who used a prescription nasal spray (mostly INS) to treat their AR in the past 4 weeks did not achieve relief from all or most of their symptoms and over half (51\%) experienced decreased effectiveness of their medication in relieving their symptoms over the course of the day or night [34]. Furthermore, dripping down the throat, bad taste and burning sensation, the most bothersome side effects of the prescription nasal sprays, were often sufficiently bothersome to cause the child to stop taking the medication, request a new medication or be non-adherent with their physician's instructions.

\section{$H_{1}$-Antihistamines}

Symptom relief with $\mathrm{H}_{1}$-antihistamines is still the predominant treatment choice for both AR and urticaria in children. The first-generation $\mathrm{H}_{1}$-antihistamines have a reportedly worse tolerability and safety profile than the newer second-generation drugs; however, surprisingly the former are widely available as OTC and as prescription medications in developing and many developed countries for the treatment of AR and urticaria in children as young as 2 years of age [38]. Furthermore, first-generation $\mathrm{H1}$-antihistamines are widely found as active ingredients in medications for insomnia $[39,40]$ as well as cough and cold [41, 42]. It is now recognised that the adverse effects, namely sedation, sleepiness or drowsiness, as well as difficulties in learning and cognitive processing associated with first-generation $\mathrm{H}_{1}$-antihistamines are a consequence of their rapid absorption and their ability to readily cross the blood-brain barrier where they bind with high affinity to the cerebral $\mathrm{H}_{1^{-}}$ receptors $[38,43]$. Although first-generation $\mathrm{H}_{1}$-antihistamines are used to 'calm children down' and to make them sleep better, there is evidence that these agents may also lead to paradoxical central excitation, restlessness, insomnia or seizures in some patients [38]. Indeed, studies investigating the effects of $\mathrm{H}_{1}$-antihistamines on sleep patterns in healthy volunteers have demonstrated that first-generation $\mathrm{H}_{1}$-antihistamines such as chlorpheniramine $[44,45]$ and promethazine [46] can significantly disturb sleep structure/architecture, as indicated by increased latencies in sleep onset and rapid eye movement sleep and reduced duration of rapid eye movement sleep and overall sleep, compared with placebo or fexofenadine, a second-generation $\mathrm{H}_{1}$-antihistamine. Given the prevalence of use of paediatric medications containing $\mathrm{H}_{1}$-antihistamines and the concerns about the potential adverse effects of these agents coupled with lack of adequate data on the efficacy and safety of these medica- 
tions, it is not surprising that regulators and practitioners alike have expressed a range of concerns about medications for sleep [40] as well as cough and cold [41, 47]. Indeed, the US Food and Drug Administration has recently conducted a public awareness campaign on the safe use of non-prescription OTC cough and cold medicines in children, and issued a nationwide public health advisory that strongly recommended against the use of these products in children under 2 years of age because of the risk of serious and potentially life-threatening side effects [48]. More specifically, this campaign was aimed at parents and caregivers to both highlight the dangers of these medicines and make specific recommendations on avoiding these dangers, namely that children should not be given medicines intended for adults, that a check should be made for the active ingredients in the medicine, that two or more medicines containing the same active ingredients should never be given together, that only measuring devices made and supplied for measuring the medicines should be used, and that manufacturers' directions on how to use the medicines should be followed carefully. A recent position paper of the Global Allergy and Asthma European Network reinforced the understanding of the scientific community about the dangers of first-generation antihistamine use, drawing attention to the fact that these medications have been implicated in civil aviation, motor vehicle and boating accidents, deaths as a result of accidental or intentional overdosing in infants and young children, and suicide in teenagers and adults [49].

Second-generation $\mathrm{H}_{1}$-antihistamines generally do not readily cross the blood-brain barrier and therefore have a lower potential for side effects of the central nervous system, compared to first-generation $\mathrm{H}_{1}$-antihistamines [50]. Additionally, the majority of second-generation $\mathrm{H}_{1}$-antihistamines bind to $\mathrm{H}_{1}$-receptors with greater specificity and have comparatively longer half-lives, thus respectively reducing or eliminating the potential for anticholinergic side effects and permitting use as once or twice daily dosage. Indeed, some second-generation $\mathrm{H}_{1-}$ antihistamines are much more adapted for use in children due to a better therapeutic index (risk/benefit ratio) and have been approved for treatment of AR and urticaria in very young children.

Although the $\mathrm{H}_{1}$-antihistamines are commonly used for the treatment of both AR and chronic idiopathic urticaria (CIU) in children, recent reviews have indicated that, in comparison with adults, only a limited number of trials of these agents have been conducted primarily in children with AR, and that data from well-designed trials in children are generally lacking $[38,43,51]$. There are many reasons for lack of data in children. Besides the considerable and challenging ethical considerations of conducting trials in patients too young to give consent themselves $[38,43]$, there are often difficulties in enrolling children into clinical trials because of the parents' and physicians' concerns about the potential side effects of the active ingredients as well as other ingredients such as sugar and excipients in medicines $[43,51]$. Conversely, parental concern about the lack of symptom relief if the child was randomised to the placebo group also plays a vital role in parents not wishing to enrol their children in placebo-controlled studies [43]. Similarly, practical and economic difficulties, including the need to conduct multiple resource-consuming and often long-term safety and pharmacokinetics studies in different age groups from the neonatal period to adolescence, the requirement for specially trained paediatric staff to conduct the trials, variability in symptom reporting, medication administration, and collection of other data resulting from children spending time with multiple caregivers [38, 43], are major factors upon which pharmaceutical companies are incentivised or not to progress with trials in paediatric patients. Although real-life observational studies are not a substitute for clinical trials, they do nevertheless offer a different perspective and means for obtaining information about a particular medication in the paediatric population. Despite limitations such as slightly less rigorous assessments and the influence of a placebo effect and other confounding factors, large-scale observational studies explore patient, parent and physician perception and satisfaction with treatment and disease management [52], and thus reveal real-life treatment acceptance and compliance.

Presently, only three $\mathrm{H}_{1}$-antihistamines (cetirizine $[53,54]$, levocetirizine [55] and loratadine [56]) have been investigated for long-term safety in the paediatric population. Both cetirizine and its follow-up compound levocetirizine have a complete and comprehensive set of safety data over an 18-month treatment period in atopic children aged 1-3 years of age. The study of loratadine collected safety information over a period of 12 months in a similarly aged paediatric population. Since levocetirizine is the only antihistamine launched in the 21st century with safety data over a very long treatment period of 18 months [55], the studies of levocetirizine are further reviewed to evaluate the suitability of this agent as a treatment option for the management of AR and CIU in children. 


\section{Studies Investigating the Efficacy and Safety of Levocetirizine in the Treatment of Allergic Disease in Paediatric Patients}

The efficacy and safety of levocetirizine has extensively been studied over the last few years in 6-month- to 12 -year-old children suffering from AR and CIU. These studies can be generally subdivided into studies involving cohorts of children aged $<6$ years and $6-12$ years, based primarily on dosing using liquid formulations or tablets, respectively.

\section{Studies in Children $<6$ Years of Age}

Cranswick et al. [57] first investigated the PK and PD profile of levocetirizine over a period of 90 days in 15 children aged 12-24 months and suffering from recurrent cough and other allergy-related symptoms. Following a baseline histamine cutaneous challenge test on day 1 , all children were treated with a levocetirizine dose of 0.125 $\mathrm{mg} / \mathrm{kg}$, from a $5 \mathrm{mg} / \mathrm{ml}$ oral solution, and blood samples were collected at regular times for up to $12 \mathrm{~h}$ for analysis of levocetirizine. From day 2 onwards, the children were administered the same dose of levocetirizine, twice a day for 90 days, and visited the laboratory for control examination at days 3-6, 30, 60 and 90. At days 3-6 and day 90 morning pre-dose blood/urine samples were collected and a histamine cutaneous challenge test was performed to assess the inhibition from baseline in the wheal and flare response. The PK parameters indicated that levocetirizine was absorbed rapidly from the gastrointestinal tract and attained mean peak plasma levels $\left(\mathrm{C}_{\max }\right) 1 \mathrm{~h}$ $\left(t_{\max }\right)$ following administration. The elimination half-life $\left(t_{1 / 2}\right)$ of levocetirizine was found to be about $4 \mathrm{~h}$ and the volume of distribution $\left(\mathrm{V}_{\mathrm{d}} / \mathrm{F}\right)$ was low $(0.37 \mathrm{l} / \mathrm{kg}$, approx. 4.3 litres), indicating an overall low potential for adverse effects. Indeed, the lack of drug-related clinical adverse events or adverse laboratory findings confirmed that levocetirizine $0.125 \mathrm{mg} / \mathrm{kg}$ twice daily, given to 1- to 2-yearold children, over 90 days, was well tolerated. Furthermore, assessment of histamine-induced wheal and flare responses demonstrated that levocetirizine $0.125 \mathrm{mg} / \mathrm{kg}$ twice daily completely inhibited histamine-induced wheals and flares (100\% inhibition) at days 3-6 and by $>98 \%$ at day 90 , suggesting high antihistaminic potency of this agent in 1- to 2-year-old children at this dose.

As levocetirizine is the pharmacologically active enantiomer of racemic cetirizine, it has been possible to characterise the population pharmacokinetics of levocetirizine in atopic children aged $1-4$ years $[58,59]$ using the large database from the Early Treatment of the Atopic
Child (ETAC ${ }^{\circledR}$ ) study $[53,54]$, the first well-controlled, long-term prospective study to investigate the effect of an antihistamine (cetirizine) in very young children. Retrospective analysis of data by non-linear mixed effects modelling has shown that in very young children both the oral clearance and the volume of distribution of levocetirizine are markedly influenced by the weight of the child and increase linearly with increasing weight $[58,59]$. Conversely, eosinophilia, allergic disease, sensitisation to allergens, use of concomitant medications (corticosteroids, penicillins, macrolides and hydroxyzine) and occurrence of diarrhoea or gastroenteritis did not influence the pharmacokinetics of levocetirizine. Assessment of the area under the curve for plasma levocetirizine concentrations at steady state indicated that this was similar to that observed in adults dosed with levocetirizine $5 \mathrm{mg}$ once daily [58]. Collectively, these findings suggest that in children aged 1-4 years or weighing $8-20 \mathrm{~kg}$, levocetirizine dosing should be based on body weight and that administration of levocetirizine $0.125 \mathrm{mg} / \mathrm{kg}$ twice daily would lead to similar exposure to levocetirizine as in adults taking the recommended therapeutic dose of $5 \mathrm{mg}$ once daily.

Compared with other commonly employed secondgeneration antihistamines levocetirizine is characterised by a favourable $\mathrm{PK}$ profile, comprising a shorter elimination half-life than that for desloratadine, ebastine, fexofenadine and loratadine [60-62], and a markedly lower volume of distribution than that for desloratadine [61, 62]. Moreover, levocetirizine is not metabolised in the liver via the cytochrome P450 enzyme system and does not have the potential for drug interactions with inhibitors of the cytochrome P450 enzyme system or other drugs which are metabolised via this system [60]. Indeed, to our knowledge, no data exist for possible drug interactions between levocetirizine and cytochrome P450 inhibitors/ drugs metabolised via this pathway in children.

The reliable tolerability and consistent safety profile of levocetirizine in the paediatric population suggested by the findings for its $\mathrm{PK}$ properties in children aged 1-4 years has recently been confirmed by a prospective, longterm, multi-national study (Early Prevention of Asthma in Atopic Children; EPAAC), which reported safety of levocetirizine $0.125 \mathrm{mg} / \mathrm{kg}$ twice daily in 1 - to 3 -year-old children with atopic dermatitis [55]. Overall, 510 atopic children were randomised to receive either levocetirizine drops $0.125 \mathrm{mg} / \mathrm{kg}$ or placebo twice daily for 18 months in a double-blind manner. Safety was assessed using numerous parameters, including any treatment-emergent adverse events and the days on which symptoms of asthma or urticaria were recorded by parents or guardians in 
Table 1. Neurologic/behavioural events reported during 18 months of treatment with either cetirizine or levocetirizine

\begin{tabular}{lll}
\hline & $\begin{array}{l}\text { Cetirizine } \\
\text { (ETAC) [54] }\end{array}$ & $\begin{array}{l}\text { Levocetirizine } \\
\text { (EPAAC) [55] }\end{array}$ \\
\hline Somnolence & $2.3 \%$ & $0 \%$ \\
Nervousness & $1.3 \%$ & $0.4 \%$ \\
Insomnia & $8.8 \%$ & $1.2 \%$ \\
Fatigue & $3.3 \%$ & $0 \%$ \\
\hline
\end{tabular}

diary cards, the numbers of children discontinuing the study due to adverse events, height and body mass measurements, assessment of psychomotor development (including developmental milestones for gross and fine motor development as well as speech and language) and laboratory tests. The authors demonstrated that there were no significant differences between the levocetirizine- and placebo-treated groups with regard to the incidence of overall or serious adverse events, drug-related adverse events or the adverse events leading to permanent discontinuation of the study medication. The most common adverse events were related to upper respiratory tract infections, transient gastroenteritis symptoms or exacerbations of allergic disease, in both groups. Indeed, not a single case of somnolence, irritability or anxiety was reported as a neurologic or behavioural adverse event in the levocetirizine-treated group. Similarly, there were no significant differences between the levocetirizine- and placebo-treated children with regard to age-appropriate development in height and body mass, attainment of all psychomotor developmental milestones or physiologic changes in haematology and biochemistry tests over the course of the entire 18-month treatment period. Although the similarly designed ETAC study $[53,54]$ has also shown treatment with cetirizine $0.25 \mathrm{mg} / \mathrm{kg}$ twice daily for 18 months to be safe and not significantly different from placebo with respect to any safety assessments in 1- to 3-year-old children, a comparison with the findings for levocetirizine in the EPAAC study [55] indicates that overall neurologic/behavioural events were less frequently reported with levocetirizine (6.3\% of the children) than with cetirizine ( $16.3 \%$ of the children), with large differences noted in the incidence of somnolence, irritability/nervousness, insomnia and fatigue (table 1).

More recently, two randomised, double-blind, parallelgroup, placebo-controlled, multi-centre studies have specifically investigated the safety of treatment with levocetirizine $1.25 \mathrm{mg}$ and matched placebo, once or twice daily, for 2 weeks, in 69 infants aged 6-11 months and 173 children aged 1-5 years, respectively, with AR or CIU [63]. The two study cohorts were treated with levocetirizine or placebo using a ratio of $2: 1$, and safety of treatment was evaluated according to treatment-emergent adverse events, changes in weight, vital signs, electrocardiogram parameters and haematologic and biochemical laboratory tests. The overall incidence of adverse events was similar in both levocetirizine- and placebo-treated groups in both studies, with $64-70.8 \%$ of the infants and $35.1-35.6 \%$ of the 1- to 5 -year-old children experiencing one or more adverse events. Most of the adverse events were of mild or moderate intensity, with mostly gastrointestinal disorders (diarrhoea, teething and constipation) in the infant group. Assessment of the change from baseline in vital signs and laboratory parameters showed no clinically relevant changes or significant differences in any outcome measures in the levocetirizine- and placebo-treated groups in either study cohort. Similarly, assessment of change in electrocardiogram parameters showed no significant changes in levocetirizine or placebo-treated groups in both studies, and none of the patients had a prolonged corrected QT interval. These findings suggest that levocetirizine $1.25 \mathrm{mg} /$ day is very well tolerated in infants as young as 6 months of age and that $2.5 \mathrm{mg} /$ day is a well-tolerated dose for 1- to 5-year-old children with AR or CIU [63].

Apart from safety and tolerability, the efficacy of levocetirizine in treating AR and CIU in very young children has also been demonstrated in recent studies. One open, multi-centre, exploratory study investigated the acceptability and safety of levocetirizine $1.25 \mathrm{mg}$ twice daily for 4 weeks in thirty 2 - to 6 -year-old children with seasonal or perennial AR [64]. Parents/guardians scored symptoms severity on a 4-point scale of 0 (absent) to 3 (severe) and noted the adverse events experienced on daily record cards over the duration of the study. Findings indicated that the total four symptoms score (T4SS; for sneezing, rhinorrhoea, nasal pruritus and ocular pruritus) was decreased from a mean baseline value of $3.08 \pm 2.14$ to 1.98 \pm 1.92 (95\% CI: -1.60 to -0.60 ) at the end of the 4-week treatment period. Although a decrease was also noted in the nasal congestion score, the magnitude of the fall in this parameter was not documented. The study further indicated that there were no treatment-related serious adverse events or withdrawal of any child from the study due to an adverse event, during the 4 -week treatment period. These findings, however, are limited in that this was an open-label and non-placebo-controlled study, and thus need to be confirmed in other well-controlled trials in a larger cohort of this patient population. 
Another randomised, double-blind, parallel-group, multi-national, long-term study has demonstrated that levocetirizine $0.125 \mathrm{mg} / \mathrm{kg}$ twice daily is efficacious in the treatment and/or prevention of urticaria in children aged 1-2 years [65]. The EPAAC study protocol was essentially employed to investigate the effect of treatment with levocetirizine drops $0.125 \mathrm{mg} / \mathrm{kg}$ twice daily or placebo twice daily for 18 months in 510 children with atopic dermatitis. Assignment to treatment group was made according to preselected randomisation factors at baseline, including sensitisation to grass pollen, house dust mite allergen and egg, maternal history of asthma, and country of residence. Over the course of the study, parents/guardians recorded the days during which urticaria was observed on diary cards, and these episodes were validated by investigators during 8 scheduled visits and any additional visits as needed. The study demonstrated that baseline characteristics were similar for both treatment groups, with regard to demographics, severity and duration of atopic dermatitis and sensitisation to allergens. Over the course of 18 months' treatment significantly fewer children treated with levocetirizine (27.5\%) experienced urticaria compared with children treated with placebo (41.6\%; p < 0.001). Similarly, both the mean number of urticaria episodes and the number of days with urticaria were significantly lower in the levocetirizine-treated group than in the placebo-treated group. Assessment of these measures in the subgroups of children with and without history of urticaria at enrolment demonstrated that the number of children with urticaria as well as the mean number of urticaria episodes and the mean number of days with urticaria were also significantly reduced in the levocetirizine-treated group compared with the placebo-treated group (fig. 1). These findings suggest that levocetirizine is not only efficacious in treatment of urticaria, but may also be efficacious in preventing/delaying the onset of urticaria in children with atopic dermatitis.

\section{Studies in Children Aged 6-12 Years}

The pharmacologic profile of levocetirizine has been investigated in children aged 6-11 years [66]. Fourteen children weighing 20-40 kg and suffering from mild AR were each administered a single dose of levocetirizine $5 \mathrm{mg}$ tablet following an overnight fast. Blood samples were collected at scheduled times over a course of $28 \mathrm{~h}$ following administration of levocetirizine and the histamine-induced wheal and flare response test was performed after collection of each blood sample for assessment of levocetirizine concentrations in plasma and antihistaminic activity of levocetirizine, respectively. The

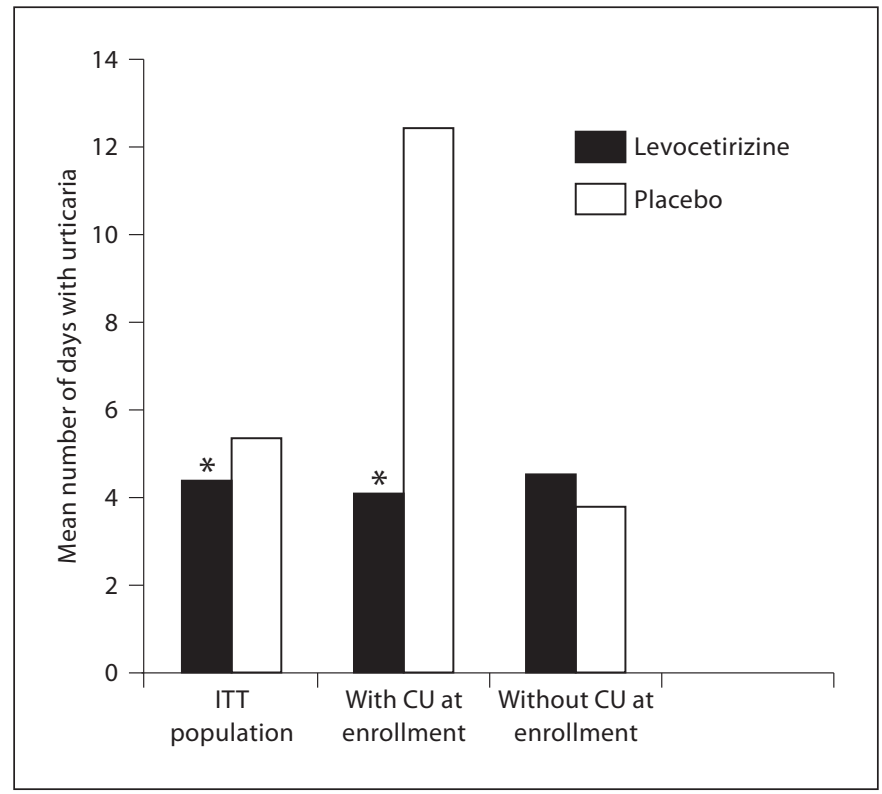

Fig. 1. Effect of treatment on chronic urticaria (CU) in intent-totreat (ITT) populations and subpopulations of children over 18 months $\left({ }^{*} \mathrm{p}<0.001\right)$. Adapted from Simons [65].

authors showed that mean maximum plasma levocetirizine concentrations were attained after a mean time of $1.2 \mathrm{~h}\left(\mathrm{t}_{\max }\right)$ and cleared at the mean terminal elimination half-life of $5.7 \mathrm{~h}\left(\mathrm{t}_{1 / 2}\right)$. A comparison of the elimination half-lives of levocetirizine and other commonly employed $\mathrm{H}_{1}$-antihistamines suggests that levocetirizine appears to be eliminated faster than the other $\mathrm{H}_{1}$-antihistamines also in this age group [60,61]. Moreover, as shown in younger children aged 1-2 years [57], the mean oral clearance rate of $0.82 \mathrm{ml} / \mathrm{min} / \mathrm{kg}$ and the mean volume of distribution $(0.4 \mathrm{l} / \mathrm{kg})$ were also found to be low in this patient cohort [66] and were lower than those for desloratadine [61]. Assessment of histamine-induced wheal and flare responses further demonstrated that levocetirizine $5 \mathrm{mg}$ significantly inhibited both histamine-induced wheals and flares from pre-dose baseline values from 1 to $28 \mathrm{~h}$, with mean maximum $97 \%$ inhibition of wheals occurring from 2 to $10 \mathrm{~h}$ after dosing and mean maximum 93\% inhibition of flares occurring from 2 to $24 \mathrm{~h}$ after dosing. These results were accompanied by 3 children reporting upper respiratory events, attributed to the underlying allergic diseases, 2 children reporting gastrointestinal symptoms considered unrelated to the study medication, and 3 children reporting fatigue attributed by the authors to the intensity of the study and considered to be possibly related to the study drug. 


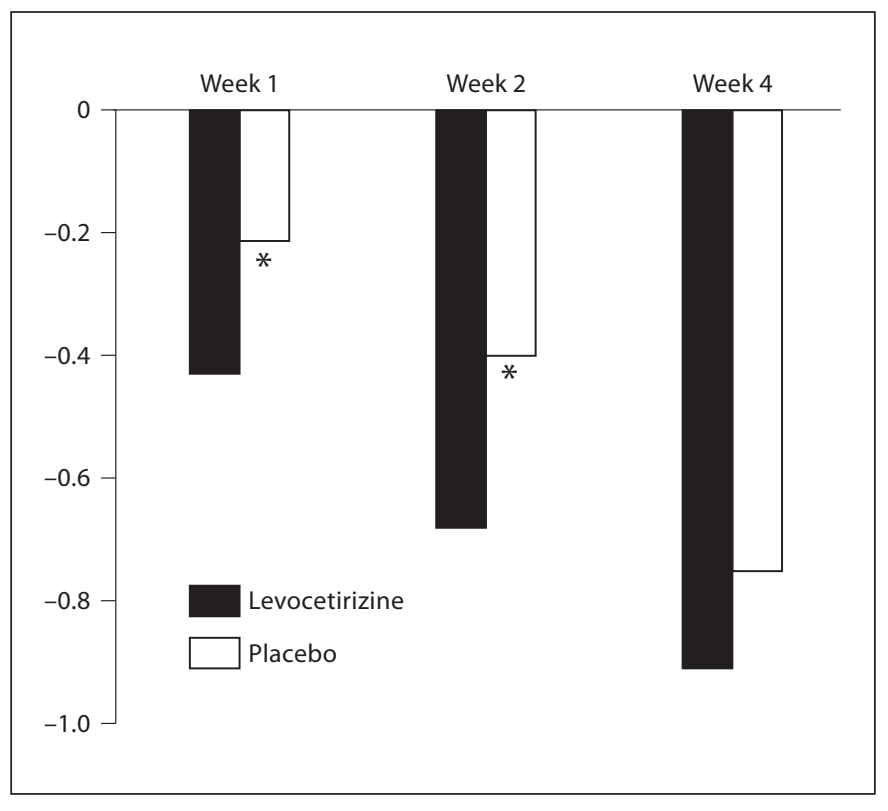

Fig. 2. PRQLQ scores over the course of 4 weeks' treatment $\left({ }^{*} \mathrm{p} \leq\right.$ 0.015). Adapted from Potter [69].

Recently, Simons et al. [67] have correlated the levocetirizine-mediated inhibition of the histamine wheal and flare response noted in these children with the peripheral $\mathrm{H}_{1}$-receptor occupancy by levocetirizine in 6- to 11-yearold children with AR. The authors showed that the peripheral $\mathrm{H}_{1}$-receptor occupancy of levocetirizine at 4 and $24 \mathrm{~h}$ after dosing were 94 and 60\%, respectively, corresponding to $95-85 \%$ flare suppression and $100-70 \%$ wheal suppression during this period. Moreover, these values at 4 and 24 $\mathrm{h}$ after dosing in children are similar to the values of 90 and $57 \%$ in adults, lending support for once daily levocetirizine $5 \mathrm{mg}$ dosing in children aged 6-11 years [67].

The safety and efficacy of levocetirizine $5 \mathrm{mg}$ once daily in the treatment of seasonal AR and perennial AR has been investigated in two randomised, double-blind, placebo-controlled, multi-centre trials $[68,69]$. The first study investigated the efficacy of levocetirizine $5 \mathrm{mg}$ once daily for 6 weeks in 177 grass and/or weed pollen-sensitised children aged 6-12 years, with seasonal AR [68]. All children scored the severity of their rhinorrhoea, sneezing, nasal pruritus and ocular pruritus (T4SS) as well as nasal congestion on a scale of 0 (absent) to 3 (severe) in daily diary cards. Additionally, change from baseline in health-related quality of life was assessed using the Paediatric Rhinoconjunctivitis Quality of Life Questionnaire (PRQLQ), and parents, physicians and children assessed the global evolution of disease on a scale of 0 (marked worsening) to 7 (marked improvement). The study showed that levocetirizine was significantly more effective than placebo in reducing the severity of mean T4SS from baseline over the entire study period $(p<0.001)$ and nearly twice as effective as placebo over the first 2 weeks of treatment. Levocetirizine also significantly improved nasal congestion over the first 5 weeks of treatment and led to overall greater improvements from baseline in individual domain and overall PRQLQ scores from week 2 onwards, compared with placebo. Over the first 2 weeks of treatment, $80-85 \%$ of parents/guardians, physicians and children were satisfied with the disease improvement with levocetirizine treatment, compared with only $53-61 \%$ of parents/guardians, physicians and children in the placebo group. Safety assessments further indicated that the two treatment groups were not significantly different with regard to incidence of adverse events. Headache, bronchitis and epistaxis were the most commonly reported study adverse events, with 10 of them considered by the investigator to be treatment related, 5 in each group. None of the adverse events were serious and only 1 placebo-treated child prematurely discontinued treatment because of safety issues.

Using a similar design, the study in children with perennial AR investigated the effect of levocetirizine $5 \mathrm{mg}$ once daily for 4 weeks on T4SS and PRQLQ scores in 306 children aged 6-12 years [69]. The investigators also recorded their global evaluation of disease evolution at the end of treatment. The results demonstrated levocetirizine to significantly improve the T4SS $(\mathrm{p}<0.01)$ at weeks 2 and 4 of treatment as well as PRQLQ overall scores ( $\mathrm{p} \leq 0.015)$ at weeks 1 and 2 of treatment, compared with placebo (fig. 2). Indeed, a significant correlation was noted between the improvements from baseline in T4SS and improvements in PRQLQ overall score at week 2 of treatment $(r=0.51 ; p<0.001)$. Analysis of the 50\% responder rate above placebo, which was considered as the level of clinical significance, indicated that the likelihood of symptom severity being halved over the first 2 weeks was 3 -fold greater with levocetirizine than with placebo $(\mathrm{p}=0.01)$. The investigators rated $57.1 \%$ of the children in the levocetirizine group as markedly or moderately improved, compared with $44.7 \%$ of the children in the placebo group. Assessment of safety parameters demonstrated that levocetirizine was not significantly different from placebo with regard to incidence or type of most common adverse events, treatment-related adverse events, or withdrawal from the study. Headache, upper respiratory tract infection and influenza were the most commonly reported study adverse events, with 7.8 and $5.9 \%$ of the levocetirizine- and placebo-treated children, respectively, experi- 


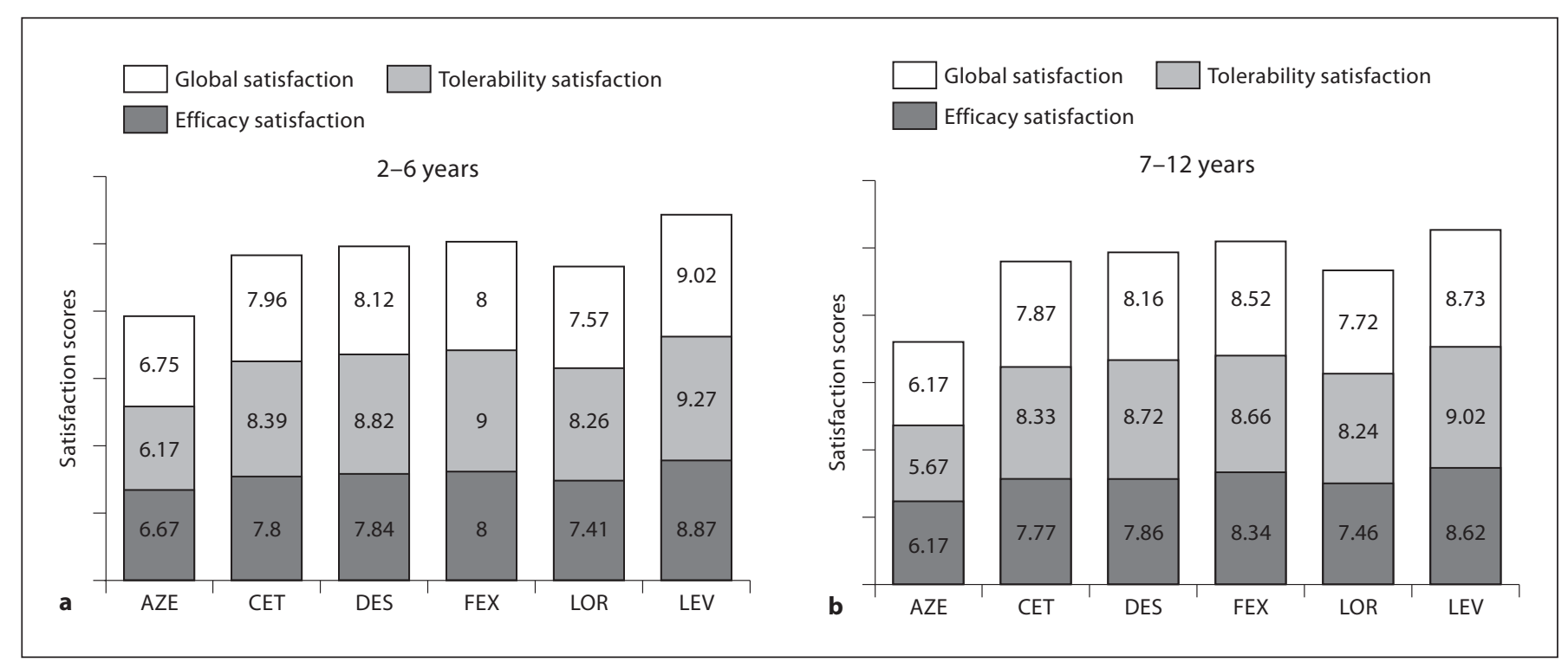

Fig. 3. Parents' mean efficacy, tolerability and global satisfaction scores with second-generation $\mathrm{H}_{1}$-antihistamines in 2- to 6-year-old (a) and 7- to 12-year-old (b) children, assessed on a visual analogue scale of 0-10. $\mathrm{AZE}=$ Azelastine CET = cetirizine DES = desloratadine FEX = fexofenadine LOR = loratadine; LEV = levocetirizine. Adapted from Ferrer et al. [70].

encing events judged as related to the study medication; 2 children from the placebo group discontinued the study due to sinobronchitis and aggravated asthma, and 2 levocetirizine-treated children discontinued due to upper respiratory tract infection and otitis media.

More recently, the international Observational Survey in Children with AR evaluated parents' and physicians' satisfaction with efficacy and tolerability of any oral $\mathrm{H}_{1}$ antihistamine treatment in children with allergic diseases [70]. A total of 4,581 children aged 2-12 years were enrolled from 424 primary care/specialist allergy clinics across 7 countries in Europe and Asia. Of these, 66.5\% of the patients suffered from AR and $14.5 \%$ of the patients from CIU as primary conditions. Parents and physicians of eligible children scored questionnaires evaluating their satisfaction with efficacy, tolerability and overall satisfaction with the $\mathrm{H}_{1}$-antihistamine used as well as the impact of this medication on the child's sleep and school performance and their willingness to use/recommend the same $\mathrm{H}_{1}$-antihistamine in the future. The authors reported that both parents and physicians were significantly more satisfied with the use of second-generation $\mathrm{H}_{1}$-antihistamines than with the use of first-generation $\mathrm{H}_{1}$-antihistamines. Assessment of the most commonly used secondgeneration $\mathrm{H}_{1}$-antihistamines indicated that levocetirizine was the most frequently used, while fexofenadine and azelastine were the least frequently used in the study cohort. Indeed, the most common use of levocetirizine was reflected by generally both the parents' and physicians' mean satisfaction scores for efficacy, tolerability and global satisfaction for levocetirizine being highest, and, together with fexofenadine, significantly greater than those for the other second-generation $\mathrm{H}_{1}$-antihistamines. Assessment of physicians' and parents' (fig. 3) satisfaction scores according to 2- to 6-year-old and 7- to 12 -year-old age groups also indicated levocetirizine to generally score higher for efficacy, tolerability and global satisfaction than the other second-generation $\mathrm{H}_{1}$-antihistamines in both age groups. Although with generally lower scores, fexofenadine, desloratadine and cetirizine were better perceived by physicians and parents than loratadine and azelastine. Similarly, the parents generally rated levocetirizine higher than the other $\mathrm{H}_{1}$-antihistamines, with fexofenadine scoring nearly as well as levocetirizine, for their positive impact on their child's quality of sleep, ability to function at school and quality of school activities (fig. 4). The number of parents and physicians willing to use or recommend the same antihistamine treatments were generally high in this observational study, at 92.1 and $92.6 \%$, respectively. Clemastine was the antihistamine with the lowest number of physicians (50\%) willing to recommend it to their patients. In terms of adverse events, this large observational study confirmed that second-generation antihistamines were associated with few- 


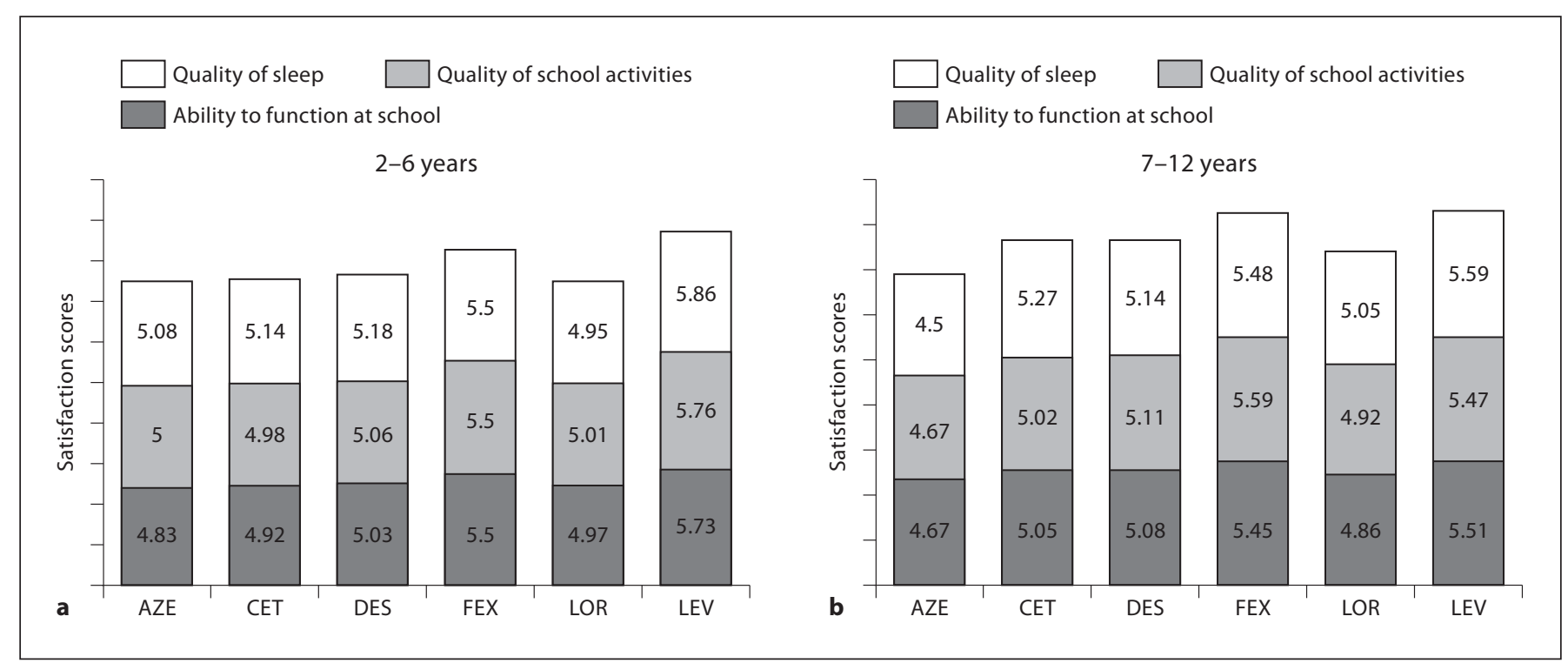

Fig. 4. Parents' mean scores for impact of last second-generation $\mathrm{H}_{1}$-antihistamine treatment on the child's quality of life measures in 2- to 6-year-old (a) and 7- to 12-year-old (b) children, assessed on a 7-point Likert scale. $\mathrm{AZE}=$ Azelastine; $\mathrm{CET}=$ cetirizine; $\mathrm{DES}=$ desloratadine; FEX = fexofenadine; $\mathrm{LOR}=$ loratadine; $\mathrm{LEV}=$ levocetirizine. Adapted from Ferrer et al. [70].

er tolerability issues than first-generation antihistamines; for example, $22.1 \%$ of patients treated with hydroxyzine, $24.0 \%$ treated with cyproheptadine, $27.8 \%$ treated with clemastine and $30.0 \%$ treated with chlorpheniramine reported adverse events, compared with $1.8 \%$ of patients on desloratadine, $2.0 \%$ on levocetirizine, $2.4 \%$ on fexofenadine, $2.5 \%$ on loratadine and $4.7 \%$ on cetirizine.

Collectively, the findings of this real-life study suggest that parents and physicians were more satisfied with second-generation antihistamines, with levocetirizine and fexofenadine being the most preferred among the $\mathrm{H}_{1}$-antihistamines currently employed for treatment of allergic disease in children aged 2-12 years, with regard to efficacy, tolerability as well as the impact on their child's sleep and school activities [70].

\section{Conclusion}

Children appear to be more affected than ever before and suffer from both persistent and severe symptoms. Due to the limited number of clinical trials in children the amended Pediatric Research Equity Act of 2007 now requires all new drugs for children to be properly assessed for 'the safety and effectiveness of the drug or the biological product for the claimed indications in all relevant pediatric sub-populations' [71]. Levocetirizine is one of the most extensively investigated antihistamines for safety and efficacy in children of different ages ranging from 6 months to 12 years. Compared with cetirizine [72], desloratadine, fexofenadine and mizolastine [73], levocetirizine seems to have a favourable PK profile with respect to absorption, plasma protein binding or volume of distribution, suggesting a potentially greater therapeutic index for this antihistamine. Real-life studies have indicated good satisfaction levels with levocetirizine for the majority of patients.

In conclusion, the use of the first-generation $\mathrm{H}_{1}$-antihistamines should undoubtedly be limited or discontinued in children suffering from AR or CIU and physicians should, whenever possible, prescribe only the new secondgeneration $\mathrm{H}_{1}$-antihistamines to children. In view of the data currently available for pharmacokinetics, clinical safety/tolerability, efficacy and general preference for levocetirizine by both parents/guardians and physicians, levocetirizine seems a suitable treatment option for AR and chronic urticaria in children aged 6 months to 12 years.

\section{Acknowledgement}

This study has been financially supported and made available as an open access article by UCB Farchim SA, Bulle, Switzerland. 


\section{References}

$\nabla_{1}$ Kearns GL, Abdel-Rahman SM, Alander SW, Blowey DL, Leeder JS, Kauffman RE: Developmental pharmacology - drug disposition, action, and therapy in infants and children. N Engl J Med 2003;349:1157-1167.

$\checkmark 2$ McKinney RE: Congress, the FDA, and the fair development of new medications for children. Pediatrics 2003;112:669-670.

$\checkmark 3$ Roberts R, Rodriguez W, Murphy D, Crescenzi T: Pediatric drug labeling: improving the safety and efficacy of pediatric therapies. J Am Med Assoc 2003;290:905911.

4 ICH (International Conference on Harmonization): ICH harmonised tripartite guideline: clinical investigation of medicinal products in the pediatric population E11. Current step 4 version dated 20 July 2000. http://www. ich.org/LOB/media/MEDIA487.pdf (accessed 5th May 2010).

5 Blaiss M: Current concepts and therapeutic strategies for allergic rhinitis in school-age children. Clin Therap 2004;26:1876-1889.

6 Mennella JA, Beauchamp GK: Optimizing oral medications for children. Clin Ther 2008;30:2120-2132.

7 Vanchieri C, Stith Butler A, Knutsen A: Addressing the barriers to pediatric drug development - workshop summary. Forum on Drug Discovery, Development, and Translation. Institute of Medicine of the National Academies. Washington D.C., National Academies Press, 2008. www.nap.edu (accessed 5th May 2010).

8 European Medicines Agency: Guideline on the role of pharmacokinetics in the development of medicinal products in the paediatric population. 2006. http://www.ema.europa. eu/pdfs/human/ewp/14701304en.pdf (accessed 5th May 2010).

9 Durmowicz E: Pediatric drug development CDER forum for international drug regulatory authorities. 2009. http://www.fda.gov/ downloads/Drugs/NewsEvents/UCM 182540.pdf (accessed 5th May 2010).

$>10$ Dunne J: The European regulation on medicines for paediatric use. Paediatr Respir Rev 2007;8:177-183.

$>11$ Mösges R, Klimek L: Today’s allergic rhinitis patients are different: new factors that may play a role. Allergy 2007:62:969-975.

- 12 Barnes C, Dinakar C, Reddy M, Portnoy J: Frequency of fungi in homes of pediatric allergy patients. Allergy Clin Immunol Int: J World Allergy Org 2006;18:197-202.

$\checkmark 13$ Mudarri D, Fisk WJ: Public health and economic impact of dampness and mold. Indoor Air 2007; 17:226-235.

-14 Bernard A, Nickmilder M, Voisin C, Sardella A: Impact of chlorinated swimming pool attendance on the respiratory health of adolescents. Pediatrics 2009;124:1110-1118.
15 Ellwood P, Asher MI, Björkstén B, Burr M, Pearce N, Robertson CF: Diet and asthma, allergic rhinoconjunctivitis and atopic eczema symptom prevalence: an ecological analysis of the International Study of Asthma and Allergies in Childhood (ISAAC) data. ISAAC Phase One Study Group. Eur Respir J 2001;17:436-443.

16 Njå F, Nystad W, Lødrup Carlsen KC, Hetlevik O, Carlsen $\mathrm{KH}$ : Effects of early intake of fruit or vegetables in relation to later asthma and allergic sensitization in school-age children. Acta Paediatr 2005;94:147-154.

17 Marshall GD: Internal and external environmental influences in allergic diseases. J Am Osteopath Assoc 2004;104(suppl 5):S2-S6.

18 Long A, McFadden C, DeVine D, Chew P, Kupelnick B, Lau J: Management of Allergic and Nonallergic Rhinitis (Evidence Report/ Technology Assessment No. 54 (Prepared by New England Medical Center EvidenceBased Practice Center under Contract No. 290-97-0019). AHRQ Pub. No. 02-E024. Rockville, MD, Agency for Healthcare Research and Quality, 2002.

19 Bousquet J, Khaltaev N, Cruz AA, et al.: Allergic rhinitis and its impact on asthma (ARIA) 2008 update (in collaboration with the World Health Organization, GA ${ }^{2}$ LEN and AllerGen). Allergy 2008;63(suppl 86):8160.

20 Bauchau V, Durham SR: Prevalence and rate of diagnosis of allergic rhinitis in Europe. Eur Respir J 2004;24:758-764.

21 Bachert C, van Cauwenberge P, Olbrecht J, van Schoor J: Prevalence, classification and perception of allergic and nonallergic rhinitis in Belgium. Allergy 2006;61:693-698.

22 The diagnosis and management of rhinitis: an updated practice parameter. Joint Task Force on Practice Parameters. J Allergy Clin Immunol 2008;122:S1-S84

23 Ceuppens J: Western lifestyle, local defenses and the rising incidence of allergic rhinitis. Acta Otorhinolaryngol Belg 2000;54:391395.

24 Asher MI, Montefort S, Björkstén B, Lai CK, Strachan DP, Weiland SK, Williams $\mathrm{H}$, ISAAC Phase Three Study Group: Worldwide time trends in the prevalence of symptoms of asthma, allergic rhinoconjunctivitis and eczema in childhood: ISAAC Phases One and Three repeat multicountry crosssectional surveys. Lancet 2006;368:733-743.

25 Galassi C, De Sario M, Biggeri A, Bisanti L, Chellini E, Ciccone G, Petronio MG, Piffer S, Sestini P, Rusconi F, Viegi G, Forastiere F: Changes in prevalence of asthma and allergies among children and adolescents in Italy: 1994-2002. Pediatrics 2006;117:34-42.

26 Liao MF, Liao MN, Lin SN, Chen JY, Huang JL: Prevalence of allergic diseases of schoolchildren in central Taiwan. From ISAAC surveys 5 years apart. J Asthma 2009;46:541545 .
27 Sánchez-Lerma B, Morales-Chirivella FJ, Peñuelas I, Blanco Guerra C, Mesa Lugo F, Aguinaga-Ontoso I, Guillén-Grima F: High prevalence of asthma and allergic diseases in children aged 6 and 7 years from the Canary Islands: the International Study of Asthma and Allergies in Childhood. J Investig Allergol Clin Immunol 2009; 19:383-390.

28 Björkstén B, Clayton T, Ellwood P, Stewart A, Strachan D; ISAAC Phase III Study Group: Worldwide time trends for symptoms of rhinitis and conjunctivitis: Phase III of the International Study of Asthma and Allergies in Childhood. Pediatr Allergy Immunol 2008; 19:110-124

-29 Canonica GW, Bousquet J, Mullol J, Scadding GK, Virchow JC: A survey of the burden of allergic rhinitis in Europe. Allergy 2007; 62(suppl)85:17-25.

30 Schatz M: A survey of the burden of allergic rhinitis in the USA. Allergy 2007;62(suppl 85):9-16.

31 Nathan RA: The burden of allergic rhinitis. Allergy Asthma Proc 2007;28:3-9.

$\checkmark 32$ Reed SD, Lee TA, McCrory DC: The economic burden of allergic rhinitis. Pharmacoeconomics 2004;22:345-361.

33 Blaiss MS: Pediatric allergic rhinitis: physical and mental complications. Allergy Asthma Proc 2007;29:1-6.

>34 Meltzer EO, Blaiss MS, Derebery MJ, Mahr TA, Gordon BR, Sheth KK, Simmons AL, Wingertzahn MA, Boyle JM: Burden of allergic rhinitis: results from the Pediatric Allergies in America survey. J Allergy Clin Immunol 2009;124(suppl 3): S43-S70.

$>35$ Scadding GK: Allergic rhinitis in children. Paed Child Health 2008;18:323-328.

-36 Röder E, Berger MY, de Groot H, van Wijk RG: Immunotherapy in children and adolescents with allergic rhinoconjunctivitis: a systematic review. Pediatr Allergy Immunol 2008;19:197-207.

-37 Bousquet PJ, Cox LS, Durham SR, et al.: Sublingual immunotherapy: World Allergy Organization Position Paper 2009. Allergy 2009;64(suppl 91):1-59.

38 Schad CA, Skoner DP: Antihistamines in the pediatric population: achieving optimal outcomes when treating seasonal allergic rhinitis and chronic urticaria. Allergy Asthma Proc 2008;29:7-13.

39 Meltzer LJ, Mindell JA, Owens JA, Byars KC: Use of sleep medications in hospitalized pediatric patients. Pediatrics 2007;119:10471055.

40 Owens JA, Rosen CL, Mindell JA: Medication use in the treatment of pediatric insomnia: results of a survey of community-based pediatricians. Pediatrics 2003;111:e628-e635. 
41 Vernacchio L, Kelly JP, Kaufman DW, Mitchell AA: Cough and cold medication use by US children, 1999-2006: results from the Slone survey. Pediatrics 2008;122:e323-e329.

42 Chang AB, Peake J, McElrea MS: Antihistamines for prolonged non-specific cough in children. Cochrane Database Syst Rev 2008; 2:CD005604. DOI: 10.1002/14651858. CD005604.pub3.

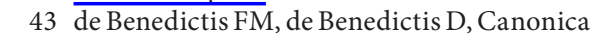
GW: New oral H1-antihistaminesin children: facts and unmet needs. Allergy 2008; 63:1395-1404.

- 44 Lee HW, Lee HW, Park DJ, Moon SO, Ahn JH, Kim MJ, Kim SD, Kim JE, Yoon YR: The effects of fexofenadine at steady-state on sleep architecture: a study using polysomnography in healthy Korean volunteers. Expert Opin Pharmacother 2008;9:1655-1665.

- 45 Boyle J, Eriksson M, Stanley N, Fujita T, Kumagi Y: Allergy medication in Japanese volunteers: treatment effect of single doses on nocturnal sleep architecture and next day residual effects. Curr Med Res Opin 2006;22: 1343-1351.

46 Risberg AM, Risberg J, Ingvar DH: Effects of promethazine on nocturnal sleep in normal man. Psychopharmacologia 1975;43:279284.

47 Sharfstein JM, North M, Serwint JR: Over the counter but no longer under the radar pediatric cough and cold medications. N Engl J Med 2007;357:2321-2324.

48 FDA: Using over-the-counter cough and cold products in children. http://www.fda. gov/downloads/ForConsumers/Consumer Updates/ucm048524.pdf (accessed 5th May 2010).

-49 Church MK, Maurer M, Simons FE, Bindslev-Jensen C, van Cauwenberge P, Bousquet J, Holgate ST, Zuberbier T: Risk of first-generation $\mathrm{H}_{1}$-antihistamines: a GA ${ }^{2} \mathrm{LEN}$ position paper. Allergy 2010;65:459-466.

-50 Holgate ST, Canonica GW, Simons FER, Taglialatela M, Tharp M, Timmerman H, Yanai K: Consensus Group on New Generation Antihistamines (CONGA): present status and recommendations. Clin Exp Allergy 2003;33:1305-1324.

51 Scadding G: Pediatric allergy medications: review of currently available formulations. Curr Med Res Opin 2009;25:2069-2079.

-52 Klimek L, Wrede H, Schuti BC, Hansen I: Patients' perception of the value of levocetirizine in allergic diseases - a multicentre observational study in Germany. Clin Drug Invest 2005;25:609-614.
53 ETAC Study Group: Allergic factors associated with the development od asthma and the influence of cetirizine in a doubleblind,randomised, placebo-controlled trial: first results of ETAC. Pediatr Allergy Immunol 1998;9:116-124.

54 Simons FER: Prospective, long-term safety evaluation of the $\mathrm{H}_{1}$-receptor antagonist cetirizine in very young children with atopic dermatitis. ETAC Study Group. Early Treatment of the Atopic Child. J Allergy Clin Immunol 1999;104:433-440.

55 Simons FER, Early Prevention of Asthma in Atopic Children (EPAAC) Study Group: Safety of levocetirizine treatment in young atopic children: an 18-month study. Pediatr Allergy Immunol 2007; 18:535-542.

-56 Grimfeld A, Holgate ST, Canonica GW, Bonini S, Borres MP, Adam D, Canseco Gonzalez C, Lobaton P, Patel P, Szczeklik A, Danzig MR, Roman I, Bismut H, Czarlewski W: Prophylactic management of children at risk for recurrent upper respiratory infections: the Preventia I Study. Clin Exp Allergy 2004;34: 1665-1672.

57 Cranswick N, Turzikova J, Hulhoven R: Levocetirizine in one-to two-year-old children pharmacokinetic and pharmacokinetic profile. Int J Clin Pharmacol Therap 2005;43: 172-177.

58 Hussein Z, Pitsiu M, Majid O, Aarons L, de Longueville $M$, Stockis A: Retrospective population pharmacokinetics of levocetirizine in atopic children receiving cetirizine: the ETAC $^{\circledR}$ study. Br J Pharmacol 2005;59: 28-37.

59 Simons FER: Population pharmacokinetics of levocetirizine in very young children: the pediatricians' perspective. Pediatr Allergy Immunol 2005; 16:97-103.

60 del Cuvillo A, Sastre J, Montoro J, Jáuregui I, Ferre M, Dávila A, Bartra J, Mullol J, Valero A: Use of antihistamines in pediatrics. J Investig Allergol Clin Immunol 2007;17(suppl 2):28-40.

61 Gupta S, Khalilieh S, Kantesaria B, Banfield C: Pharmacokinetics of desloratadine in children between 2 and 11 years of age. $\mathrm{Br} \mathrm{J}$ Clin Pharmacol 2007;63:534-540.

62 Gupta S, Kantesaria B, Banfield C, Wang Z: Desloratadine dose selection in children aged 6 months to 2 years: comparison of population pharmacokinetics between children and adults. Br J Clin Pharmacol 2007;64:174184.
63 Hampel F, Ratner P, Haeusler JMC: Safety and tolerability of levocetirizine dihydrochloride in infants and children with allergic rhinitis or chronic urticaria. Allergy Asthma Proc 2010;31;290-295.

64 Billard E, Dubreil Y, Pujazon MC, Lévy J, Wessel F: Safety, acceptability and efficacy of levocetirizine in 2-6 year old children with allergic rhinitis. Abstract presented at ACAAI-HSACI Joint Allergy Symposium, Athens, 2006

65 Simons FER: $\mathrm{H}_{1}$-antihistamine treatment in young atopic children: effect on urticaria. Ann Allergy Asthma Immunol 2007;99:261266

66 Simons FER, Simons KJ: Levocetirizine: pharmacokinetics and pharmacokinetics in children age 6 to 11 years. J Allergy Clin Immunol 2005;116:355-361.

-67 Simons KJ, Strolin Benedetti M, Simons FER, Gillard M, Baltes E: Relevancy of $\mathrm{H}_{1^{-}}$ receptor occupancy to $\mathrm{H}_{1}$-antihistamine dosing in children. J Allergy Clin Immunol 2007;119:1551-1554.

- 68 de Blic J, Wahn U, Billard E, Alt R, Pujazon MC: Levocetirizine in children: evidenced efficacy and safety in a 6-week randomized seasonal allergic rhinitis trial. Pediatr Allergy Immunol 2005;16:267-275.

69 Potter PC: Efficacy and safety of levocetirizine on symptoms and health-related quality of life of children with perennial allergic rhinitis: a double-blind, placebo-controlled randomized clinical trial. Ann Allergy Asthma Immunol 2005;95:175-180.

70 Ferrer M, Morais-Almeida M, Guizova M, Khanferyan R: Evaluation of treatment satisfaction in children with allergic disease treated with an antihistamine. Clin Drug Invest 2010;30:15-34

71 FDAAA: Title IV: Pediatric Research Equity Act of 2007. http://www.fda.gov/Drugs/Development ApprovalProcess/DevelopmentResources/ucm049867.htm (accessed 5th May 2010)

-72 Baltes E, Coupez R, Giezek H, Voss G, Meyerhoff C, Strolin Benedetti M: Absorption and disposition of levocetirizine, the eutomer of cetirizine, administered alone or as cetirizine to healthy volunteers. Fundam Clin Pharmacol 2001;15:269-277.

-73 Molimard M, Diquet B, Strolin Benedetti M: Comparison of pharmacokinetics and metabolism of desloratadine, fexofenadine, levocetirizine and mizolastine in humans. Fundam Clin Pharmacol 2004;18:399-411. 